\title{
PERAN PERSEPSI PENGEMBANGAN KARIR, KEDISIPLINAN KERJA DAN KEPEMIMPINAN TERHADAP KINERJA
}

\author{
Yessica Novianti \\ Program Studi Magister Manajemen Universitas Tarumanagara \\ yessicanovianti@yahoo.com \\ Mukti Rahardjo \\ Program Studi Magister Manajemen Universitas Tarumanagara
}

Masuk : 06-12-2019, revisi : 20-12-2019 diterima untuk diterbitkan : 21-12-2019

\begin{abstract}
The purpose of this study is to determine the role of career development, work discipline, and leadership on employee performance. This research method uses quantitative descriptive research. This quantitative descriptive research aims to explain various conditions, various situations or various variables that arise. The sample of this study was taken from 79 employee respondents in one of the interior contracting companies in West Jakarta. Data analysis techniques used in this study are statistical hypotheses and testing, which consist of validity, reliability, classic assumption tests (normality test, multicollinearity test, heteroscedasticity test, multiple linear regression test), and hypothesis testing methods ( $\mathrm{T}$ test, $\mathrm{F}$ test, determination coefficient analysis (R2), correlation coefficient analysis (R)). The results are: (a) There is a positive role in career development in employee performance; (b) There is a positive role for work discipline in the performance of customer employees; (c) There is a positive role of leadership in employee performance; (d) The role of career development, work discipline, and leadership has a positive influence on employee performance, which can be concluded that if the three variables increase, employee performance is also positive or increased.
\end{abstract}

Keywords : Career Development; Work Discipline, Leadership; Employee Performance

\begin{abstract}
Abstrak : Tujuan dari penelitian ini adalah untuk mengetahui peran pengembangan karir, disiplin kerja, dan kepemimpinan terhadap kinerja karyawan. Metode penelitian ini menggunakan penelitian deskriptif kuantitatif. Penelitian deskriptif kuantitatif ini bertujuan untuk menjelaskan berbagai kondisi, berbagai situasi atau berbagai variabel yang muncul. Sampel penelitian ini diambil dari 79 responden karyawan di salah satu perusahaan kontraktor interior di Jakarta Barat. Teknik analisis data yang digunakan dalam penelitian ini adalah hipotesis statistik dan pengujian, yang terdiri dari validitas, reliabilitas, tes asumsi klasik (tes normalitas, tes multikolinieritas, tes heteroskedastisitas, uji regresi linier berganda), dan metode pengujian hipotesis (uji T, uji F, analisis koefisien determinasi (R2), analisis koefisien korelasi (R)). Hasilnya adalah: (a) Ada peran positif dalam pengembangan karir dalam kinerja karyawan; (B) Ada peran positif untuk disiplin kerja dalam kinerja karyawan pelanggan; (c) Ada peran positif kepemimpinan dalam kinerja karyawan; (d) Peran pengembangan karir, disiplin kerja, dan kepemimpinan memiliki pengaruh positif terhadap kinerja karyawan, yang dapat disimpulkan bahwa jika ketiga variabel meningkat, kinerja karyawan juga positif atau meningkat.
\end{abstract}

Kata Kunci : Pengembangan Karir; Disiplin Kerja; Kepemimpinan; Kinerja Karyawan 


\section{PENDAHULUAN}

Kinerja (performance) adalah kuantitas dan atau kualitas hasil kerja individu atau sekelompok di dalam organisasi dalam melaksanakan tugas pokok dan fungsi yang berpedoman pada norma, standard operasional prosedur, kriteria dan ukuran yang telah ditetapkan atau yang berlaku dalam organisasi.

Keberadaan sumber daya manusia di dalam suatu organisasi memegang peranan yang sangat penting. Sebagai tenaga kerja, sumber daya manusia memiliki potensi yang besar untuk menjalankan aktivitas organisasi. Potensi setiap sumber daya manusia yang ada dalam organisasi harus dapat dimanfaatkan dengan sebaik-baiknya sehingga mampu memberikan output optimal. Sumber daya manusia atau karyawan dalam suatu perusahaan adalah kesatuan yang tidak dapat dipisahkan. Organisasi suatu perusahaan dapat berjalan sesuai dengan harapan apabila didalamnya terdapat karyawan yang mempunyai tujuan yang sama.

\section{TUJUAN PENELITIAN}

1. Mengetahui apakah pengembangan karir mempunyai peran terhadap kinerja.

2. Mengetahui apakah kedisiplinan kerja mempunyai peran terhadap kinerja.

3. Mengetahui apakah kepemimpinan mempunyai peran terhadap kinerja.

4. Mengetahui apakah pengembangan karir, kedisiplinan kerja, dan kepemimpinan secara simultan mempunyai peran terhadap kinerja.

\section{TELAAH PUSTAKA}

Menurut Koopmans et al (2014), kinerja karyawan merupakan suatu perilaku atau tindakan yang relevan dengan tujuan organisasi. Kinerja ini lebih menekankan pada pola perilaku dan tindakan karyawan dibandingkan dengan hasil dari perilaku itu sendiri. Hal ini berisi perilaku yang berada dibawah kontrol dari individu itu sendiri, kecuali perilaku tersebut dipengaruhi oleh lingkungannya.

Menurut Koopmans et al. (2014: 334), faktor-faktor yang dapat dijadikan indikator kinerja karyawan adalah Task Performance, Contextual Performance, Adaptive Performance, dan Counterproductive Work Behavior.

Berdasarkan hipotesis tersebut, maka peneliti mengemukakan definisi operasionalnya sebagai berikut :

1. Peran merupakan aspek dinamis kedudukan (status), apabila seseorang melaksanakan hak dan kewajibannya sesuai dengan kedudukannya, maka ia menjalankan suatu peranan (Soerjono Soekanto, 2002)

2. Pengembangan karir adalah proses peningkatan kemampuan kerja individu yang dicapai dalam rangka mencapai karir yang diinginkan (Veitzhal Rivai, 2008)

3. Kedisiplinan merupakan fungsi operatif MSDM yang terpenting, hal ini dikarenakan semakin baik disiplin karyawan, semakin tinggi prestasi kerja yang dapat dicapainya, tanpa disiplin yang baik, sulit bagi organisasi perusahaan mencapai hasil yang optimal (Hasibuan, 2013)

4. Kepemimpinan adalah kemampuan seseorang pemimpin untuk mempengaruhi orang lain dengan cara memancing tumbuhnya perasaan yang positif dalam diri orang-orang yang dipimpinnya untuk mencapai tujuan yang diinginkan (Veitzhal Rivai, 2012)

5. Kinerja karyawan merupakan suatu perilaku atau tindakan yang relevan dengan tujuan organisasi (Koopmans et al, 2014)

\section{METODE PENELITIAN}

Populasi dan Metode Pengambilan Sampel. Populasi dalam penelitian ini adalah karyawan di salah satu perusahaan kontraktor interior di Jakarta Barat. Ukuran sampel yang digunakan dalam penelitian ini adalah 79 orang. Metode pengambilan sampel yang digunakan 
adalah penelitian deskriptif kuantitatif, yang bertujuan untuk menjelaskan berbagai kondisi, berbagai situasi atau berbagai variabel yang timbul.

Variabel dan Pengukuran. Variabel dalam penelitian ini dibagi menjadi dua, yaitu varibel bebas dan variabel terikat. Variabel bebas adala variabel yang nilainya tidak dipengaruhi variabel yang lain, sedangkan variabel terikat merupakan variabel yang nilainya dipengaruhi oleh variabel bebas. Variabel bebas dalam penelitian ini adalah Pengembangan Karir (X1), Disiplin Kerja (X2) dan Kepemimpinan (X3). Sedangkan variabel terikat pada penelitian ini adalah Kinerja Karyawan (Y).

Metode Analisis Data. Teknik analisis data yang digunakan dalam penelitian ini adalah hipotesis statistik dan pengujian, yang dimana terdiri dari uji validitas, reliabilitas, uji asumsi klasik (uji normalitas, uji multikolinearitas, uji heteroskedastisitas, Uji Regresi Linier Berganda), dan metode pengujian hipotesis (uji T, uji F, Analisis Koefisien Determinasi (R2), Analisis Koefisien Korelasi (R))

\section{ANALISIS DAN BAHASAN TEMUAN}

\section{Tabel 1}

Hasil Uji F

\begin{tabular}{|l|r|r|r|r|c|}
\hline & \multicolumn{1}{|c|}{$\begin{array}{c}\text { Sum of } \\
\text { Squares }\end{array}$} & \multicolumn{1}{c|}{ df } & $\begin{array}{c}\text { Mean } \\
\text { Square }\end{array}$ & F & Sig. \\
\hline Regression & 7,134 & 3 & 2,378 & 45,000 &, $000^{\mathrm{b}}$ \\
Residual & 3,963 & 75 &, 053 & & \\
Total & 11,098 & 78 & & & \\
\hline
\end{tabular}

a. Dependent Variable: Kinerja Karyawan

b. Predictors: (Constant), Kepemimpinan, Pengembangan Karir, Disiplin Kerja

Berdasarkan data tabel di atas, diperoleh tingkat signifikansi sebesar 0,000 yang menunjukan bahwa angka tersebut lebih kecil dari 0,05. Hal ini dapat kita simpulkan bahwa $\mathrm{H}_{0}$ ditolak maka dapat disimpulkan bahwa terdapat pengaruh yang signifikan dari variabel Pengembangan Karir, Disiplin Kerja, dan Gaya Kepemimpinan terhadap Kinerja Karyawan.

Tabel 2

\section{Hasil Uji T}

\begin{tabular}{|l|c|c|c|c|c|c|c|}
\hline \multirow{2}{*}{ Model } & \multicolumn{2}{|c|}{$\begin{array}{c}\text { Unstandardized } \\
\text { Coefficients }\end{array}$} & $\begin{array}{c}\text { Standardized } \\
\text { Coefficients }\end{array}$ & \multirow{2}{*}{$\mathbf{2}$} & \multicolumn{2}{|c|}{$\begin{array}{c}\text { Collinearity } \\
\text { Statistics }\end{array}$} \\
\cline { 2 - 4 } \cline { 6 - 8 } & B & $\begin{array}{c}\text { Std. } \\
\text { Error }\end{array}$ & Beta & & & Tolerance & VIF \\
\hline 1 (Constant) & 1,887 &, 196 & & 9,618 &, 000 & & \\
$\begin{array}{l}\text { Pengembangan } \\
\text { Karir }\end{array}$ &, 182 &, 060 &, 280 & 3,058 &, 003 &, 567 & 1,765 \\
Disiplin Kerja &, 223 &, 062 &, 351 & 3,610 &, 001 &, 504 & 1,983 \\
Gaya &, 203 &, 066 &, 297 & 3,071 &, 003 &, 510 & 1,962 \\
Kepemimpinan & & & & & & & \\
\hline
\end{tabular}

Berdasarkan data dari tabel di atas, diperoleh variabel pengembangan karir memiliki nilai signifikansi sebesar 0,003 , variabel disiplin kerja memiliki nilai signifikansi sebesar 0,001 , dan variabel gaya kepemimpinan memiliki nilai signifikansi sebesar 0,003 . Nilai signifikansi ketiga variabelnya lebih kecil dari 0,05, dimana hal ini menunjukan bahwa terdapat peran pengembangan karir, disiplin kerja dan gaya kepemimpinan terhadap kinerja, yang artinya Ha1, Ha2 dan Ha3 diterima. 


\section{Tabel 3}

Hasil Uji Koefisien Determinasi (R2)

\begin{tabular}{|c|c|c|c|c|}
\hline Model & $\mathrm{R}$ & R Square & $\begin{array}{c}\text { Adjusted } \\
\text { R Square }\end{array}$ & $\begin{array}{c}\text { Std. Error of the } \\
\text { Estimate }\end{array}$ \\
\hline 1 &, $802^{\mathrm{a}}$ &, 643 &, 629 &, 22988 \\
\hline
\end{tabular}

a. Predictors: (Constant), Kepemimpinan, Pengembangan Karir, Disiplin Kerja

b. Dependent Variable: Kinerja Karyawan

Berdasarkan tabel diatas dapat dilihat nilai koefisien determinasi adalah sebesar 0,629. Berdasarkan hasil tersebut dapat disimpulkan bahwa sebesar 62,9\% variabel dependennya (kinerja karyawan) dapat dijelaskan oleh variabel independen yaitu pengembangan karir, disiplin kerja dan gaya kepemimpinan sedangkan sisanya yaitu sebesar 37,1\% (100\%-62.9\%) dijelaskan oleh variabel-variabel lainnya yang tidak diungkapkan dalam penelitian ini.

Tabel 4

Hasil Uji Koefisien Korelasi (R)

\begin{tabular}{|c|c|c|c|c|}
\hline Model & R & R Square & $\begin{array}{c}\text { Adjusted } \\
\text { R Square }\end{array}$ & $\begin{array}{c}\text { Std. Error of the } \\
\text { Estimate }\end{array}$ \\
\hline 1 &, $802^{\mathrm{a}}$ &, 643 &, 629 &, 22988 \\
\hline
\end{tabular}
a. Predictors: (Constant), Kepemimpinan, Pengembangan Karir, Disiplin Kerja
b. Dependent Variable: Kinerja Karyawan

Berdasarkan tabel diatas, diperoleh nilai korelasi (R) sebesar 0,802. Berdasarkan hasil tersebut dapat disimpulkan bahwa hubungan antara variabel pengembangan karir, disiplin kerja, dan gaya kepemimpinan terhadap kinerja karyawan adalah sangat kuat. Hal tersebut dapat dilihat dari nilai $\mathrm{R}$ yang semakin mendekati satu.

Tabel 5

Hasil Uji Hipotesis

\begin{tabular}{|l|c|c|c|}
\hline \multicolumn{1}{|c|}{ Hipotesis } & $\begin{array}{c}\text { Nilai } \\
\text { Signifikansi }\end{array}$ & $\begin{array}{c}\text { Hasil } \\
\text { Pengujian }\end{array}$ & $\begin{array}{c}\text { Hipotesis } \\
\text { Diterima/Ditolak }\end{array}$ \\
\hline Ha1: & 0,003 & Sig $<0,05$ & Ha1 diterima \\
$\begin{array}{l}\text { Terdapat peran } \\
\text { pengembangan karir } \\
\text { terhadap kinerja } \\
\text { karyawan peran }\end{array}$ & & & \\
\hline $\begin{array}{l}\text { Ha2: kerja } \\
\begin{array}{l}\text { Terdapat } \\
\text { disiplin } \\
\text { terhadap kinerja } \\
\text { karyawan }\end{array}\end{array}$ & 0,001 & Sig $<0,05$ & Ha2 diterima \\
\hline $\begin{array}{l}\text { Ha3: } \\
\begin{array}{l}\text { Terdapat peran gaya } \\
\text { kepemimpinan } \\
\text { terhadap kinerja } \\
\text { karyawan }\end{array}\end{array}$ & 0,003 & Sig $<0,05$ & Ha3 diterima \\
\hline
\end{tabular}


Berdasarkan hasil uji yang telah dilakukan dari hasil jawaban kuesioner yang diisi oleh 79 karyawan di salah satu perusahaan kontraktor interior di Jakarta Barat, didapatkan hasil bahwa Pengembangan Karir, Kedisiplinan Kerja, dan Gaya Kepemimpinan memberikan pengaruh secara simultan sebesar 0,629 atau 62,9\% yang kemudian sisanya dipengaruhi oleh faktor lain diluar model.

\section{KESIMPULAN DAN SARAN \\ Kesimpulan}

Berdasarkan dari hasil penelitian analisis yang sudah di bahas dalam bab IV, maka dapat disimpulkan sebagai berikut:

1. Terdapat peran positif pengembangan karir terhadap kinerja karyawan.

2. Terdapat peran positif kedisiplinan kerja terhadap kinerja karyawan.

3. Terdapat peran positif kepemimpinan terhadap kinerja karyawan.

4. Peran pengembangan karir, kedisiplinan kerja, dan kepemimpinan memiliki pengaruh positif terhadap kinerja karyawan, dimana dapat disimpulkan bahwa bila ketiga variabel itu meningkat maka kinerja karyawan juga positif atau meningkat.

\section{Saran}

Terkait dengan hasil penelitian diatas, maka peneliti akan memberikan beberapa saran yang sekiranya bisa bermanfaat bagi perusahaan dan bagi peneliti lain, antara lain sebagai berikut:

1. Peneliti menyarankan agar perusahaan kontraktor interior di Jakarta Barat (atau disebut dengan PT. XYZ) bisa lebih meningkatkan sistem pengembangan karir dalam perusahaannya, agar kinerja karyawan pun dapat semankin semangat dalam bekerja dan berperan positif untuk kinerja para karyawannya.

2. Bagi penelitian selanjutnya, peneliti menyarankan agar memperluas jangkauan pengambilan sampelnya. Hal tersebut bertujuan agar memperkuat dan melengkapi penelitian sebelumnya.

3. Bagi penelitian selanjutnya, peneliti menyarankan agar dapat menambah variabel baru lainnya agar mengetahui variabel apalagi yang berpengaruh terhadap kinerja karyawan.

\section{DAFTAR PUSTAKA}

Armstrong, M. (2000). Manajemen Sumber Daya Manusia. Jakarta : Erlangga

Ayer, Johanes Eliezer Johanes., Lyndon R.J Pangemanan, Yolanda P.I. Rori. (2016). Pengaruh Motivasi dan Disiplin Kerja Terhadap Kinerja Pegawai Pada Dinas Pertanian Kabupaten Supiori. Vol 12 No 3A. 1907-4298

Bahrum, SyazhashahPutra., Inggrid Wahyuni Sinaga. (2015). Pengaruh Kepemimpinan dan Motivasi Kerja Terhadap Kinerja Pegawai. Vol 3 No 2, 135-141

Efriyaningsih, Meina Eka. (2017). Pengaruh Pengembangan Karir dan Komitmen Kerja Terhadap Kinerja Karyawan PT. Bank BRI Kantor Cabang Teluk Betung Kota Bandar Lampung.

Febriansah, Rizky Eka. (2016). Pengaruh Pengembangan Karier Terhadap Kinerja Karyawan Melalui Kepuasan Karier, dan Komitmen Karier sebagai Variabel Intervening. 394-405

Hasibuan, Malayu S.P. (2003). Manajemen Sumber Daya Manusia. Edisi Revisi, Cetakan Keenam, Penerbit PT. Bumi Aksara. Jakarta.

Hery. (2015). Analisis Kerja Manajemen. Jakarta : Grasindo

Kopmans. (2014). Measuring individual work performance. Amsterdam, NLD : Institude for health and care research.

Mangkunegara, (2000). Manajemen Sumber Daya Manusia Perusahaan. Bandung: Remaja Rosdakarya. 
Nawawi, Hadari. (2003). Manajemen Sumber Daya Manusia Untuk Bisnis yang Kompetitif. Cetakan Kelima. Yogyakarta: Gadjha Mada University Press.

Nazir, Moh. (2005). Metode Penelitian. Jakarta : Ghalia Indonesia.

Notoatmodjo, S. (1998). Pengembangan Sumber Daya Manusia. Edisi Revisi. Jakarta : PT Rineka Cipta

Oposma, Meri, Rizky Natassia, Yosi Eka Putri. (2013). Pengaruh Kepemimpinan dan Motivasi Kerja Terhadap Kinerja Karyawan Pada Perusahaan Daerah Air Minum (PDAM) Kota Padang. 2302-1590

Siswanto, Rendyka Dio \& Djambur Hamid. (2017). Pengaruh Gaya Kepemimpinan Terhadap Kinerja Karyawan PT. Freeport Indonesia, 189-198

Sugiono. (2012). Metode Penelitian Kuantitatif Kualitatif dan R\&D. Bandung : Alfabeta

Yukl, Gary A. (2005). Kepemimpinan Dalam Organisasi. Edisi Kelima. Jakarta : PT. Indeks 